\title{
Las políticas de discriminación positiva en Francia
}

\author{
Eguzki Urteaga
}

Universidad del País Vasco. Departamento de Sociología 1

eguzki.urteaga@ehu.es

Recibido: 06-11-2008

Aceptado: 10-03-2009

\section{Resumen}

Las políticas de discriminación positiva consisten en crear jurídicamente unas desigualdades para favorecer la igualdad de hecho. En el momento en el cual se impone el principio de no-discriminación, puede parecer paradójico recurrir a esta forma de acción positiva cuya finalidad es llegar a una igualdad real, "dando más a los que tienen menos». Todo ello genera una serie de cuestiones: ¿Cuáles son los fundamentos de la discriminación positiva? ¿En qué condiciones es aceptable? ¿Cuáles son sus formas y sus modalidades de aplicación? ¿Cuáles son sus resultados? El caso francés es interesante. A su propósito, defendemos la hipótesis según la cual, si bien la noción de discriminación positiva choca frontalmente con el principio republicano de igualdad de todos los ciudadanos ante la ley, en la práctica, además de tolerar su uso, las administraciones públicas fomentan las políticas de acción positiva en los ámbitos del empleo, de la paridad entre hombres y mujeres en la esfera pública y de la ordenación del territorio.

Palabras clave: políticas públicas, desigualdad, paridad.

\section{Abstract. Affirmative action policies in France}

Affirmative action policies consist on legally creating some inequalities to favour real equality. However, when the principle of non-discrimination is established, it may seem paradoxical to use these policies in order to achieve real equality, thus «giving more to those who have less». This suggest several questions: What are the foundations of affirmative action? Under what conditions is it acceptable? What are its forms and ways of application? What are its results? The French case is interesting in those respects. The article defends the hypothesis that, although affirmative action strongly collides with the republican principle of equality among citizens, in practice the government not only tolerates its use, but encourages it in the areas of employment, gender parity in the public sphere, and territorial planning.

Key words: public policy, inequalities, parity. 


\title{
Sumario
}

\begin{abstract}
Introducción Conclusión
Políticas preferentes en materia de empleo Bibliografía
\end{abstract}

La igualdad de género en la esfera pública

\section{Introducción}

Tanto en el derecho internacional como en las legislaciones nacionales, la discriminación positiva es el instrumento clave de una política de reducción de las desigualdades entre los diferentes grupos sociales. Pretende promover una mayor igualdad de hecho o, por lo menos, garantizar a los miembros de los grupos con desventaja una verdadera igualdad de oportunidades. Obedece a una lógica de compensación de una diferencia de desarrollo económico y social. Por lo tanto, supone, más que un tratamiento diferenciado, la instauración de un verdadero trato preferente. Por definición, éste tiene vocación de desaparecer cuando el grupo o los grupos concernidos habrán superado su deficiencia y recuperado su retraso con respecto al resto de la sociedad.

En Francia, Nicolas Sarkozy, entonces ministro del Interior, declara que: "cuando se crean cuotas para las personas discapacitadas, cuando se legisla para que el $50 \%$ de las mujeres se encuentren sobre las listas electorales, cuando se crean zonas francas o zonas de educación prioritaria, ¿qué se hace si no se trata de discriminación positiva?». Estas declaraciones contrastan con la cautela de los responsables políticos y las críticas que genera la expresión «discriminación positiva» en un país marcado por la cultura republicana y la prepotencia del principio de igualdad de derechos y de oportunidades entre todos los ciudadanos, independientemente de su sexo, categoría social u origen geográfico.

Desde el punto de vista de los países que han desarrollado políticas de discriminación positiva, Francia aparece como un país poco hospitalario que privilegia las técnicas preferentes: el Estado dispone tradicionalmente de una gran libertad para introducir mecanismos correctores en el funcionamiento de los diferentes mercados y recurre a la ley para reequilibrar una situación de competencia desigual que es percibida como una acción legítima e incluso necesaria. Esta influencia del Estado aparece claramente en los tres ámbitos en los que aplica la política de discriminación positiva: el empleo, la esfera electoral y la ordenación del territorio. Desde hace treinta años, el desarrollo de políticas preferentes en estos ámbitos sólo ha sido obstaculizado por un imperativo de respeto de las leyes del mercado.

Pero si la técnica de discriminación positiva se integra en el funcionamiento político-administrativo francés, el espíritu de este dispositivo centrado en el grupo le es completamente ajeno. Unos principios constitucionales claramente enunciados, traducidos a nivel legislativo por dispositivos explícitos, prohíben conceder cualquier consideración positiva a las nociones de «origen étnico» o de «raza». Semejantes criterios no pueden permitir diferenciar a los 
individuos unos de otros. La Constitución gala, en su artículo 1, «asegura la igualdad ante la ley de todos los ciudadanos, sin distinción de origen, de raza o de religión» ${ }^{1}$. Los principios fundadores del orden jurídico republicano se oponen «a que sean reconocidos unos derechos colectivos a cualquier grupo que sea definido por una comunidad de origen, de cultura, de lengua o de creencia» ${ }^{2}$. Así, una oferta de empleo donde se manifiesta una preferencia para un joven inmigrante ha sido ilegalizada por su inconstitucionalidad ${ }^{3}$. Sin embargo, este marco evoluciona con el tiempo y el análisis de las tres grandes políticas de discriminación positiva ofrece un punto de vista privilegiado sobre la evolución del modelo republicano, como consecuencia del avance del liberalismo económico y de la generalización de la diversidad cultural.

En este sentido, defendemos la hipótesis según la cual, si la noción de discriminación positiva choca frontalmente con el principio republicano de igualdad de todos los ciudadanos ante la ley, en la práctica, además de tolerar su uso, las administraciones públicas fomentan las políticas de acción positiva en los ámbitos del empleo, de la paridad entre hombres y mujeres en la esfera pública y de la ordenación del territorio. En el presente artículo, analizaremos más detalladamente las políticas preferentes en materia de empleo y de igualdad de género.

\section{Políticas preferentes en materia de empleo}

Desde la mitad de la década de 1970, las políticas de inserción y, posteriormente, de lucha contra el desempleo constan de una serie de medidas que imponen a los empleadores el respeto de las prioridades e incluso la obligación de empleo o los incitan a contratar ciertas categorías de personas. El juez constitucional admite perfectamente el principio de estos empleos «ayudados» o "protegidos», teniendo en cuenta «las dificultades y las discapacidades que pueden incidir sobre la inserción profesional de las personas concernidas» ${ }^{4}$. Estas políticas son de naturaleza selectiva. No obstante, no provocan ninguna modificación drástica del juego de la oferta y de la demanda en el mercado laboral o de las reglas que rigen el acceso a la función pública: las disposiciones en vigor son poco coactivas y son, en realidad, muy poco preferentes, lo que no es de sorprender para unas medidas cuyo desarrollo ha coincidido con la aparición del desempleo masivo. Por lo tanto, considerar estas políticas de empleo como medidas de discriminación positiva no es tan evidente; más aún sabiendo que no tienen exclusivamente como objetivo la compensación de las desigualdades de hecho. Sus finalidades son variadas, incluso múltiples.

1. Constitución francesa de la Quinta República.

2. Consejo Constitucional, decisión sobre la Carta europea de las lenguas regionales o minoritarias del 15 de junio de 1999.

3. Tribunal de apelación de Nimes, decisión del 22 de noviembre de 2002.

4. Decisión del 25 de julio de 1989, Ley sobre diversas disposiciones sociales. 


\section{Unas politicas heterogéneas}

Las prioridades del empleo y las medidas de incitación a la contratación de ciertas categorías de la población son numerosas en la legislación gala.

\section{Obedecen a tres justificaciones}

Las medidas correctoras aprobadas en materia de acceso al empleo público o privado persiguen varios objetivos. Los «empleos reservados», que la Administración civil destina a los militares de carrera, expresan, por ejemplo, una voluntad del Estado de recompensar algunos de sus servidores. No obstante, se puede considerar que la mayoría de las discriminaciones positivas se refiere, alternativamente o acumulativamente, a una lógica de solidaridad nacional, a una política de inserción y/o a un discurso sobre la diversidad. La política de discriminación positiva francesa más antigua y mejor conocida ha sido aprobada en nombre de la solidaridad nacional. La ley del 26 de abril de 1924 instaura, efectivamente, en beneficio de los mutilados de guerra, una obligación de empleo a la cual deben someterse las administraciones y las empresas de más de diez trabajadores. La tasa de empleo obligatorio se fija en el $10 \%$ de la plantilla global, pero un sistema de canon permite a los empleados sustraerse a la cuota que se les impone (seis francos al día por cada mutilado no empleado).

Como sucede para la mayoría de las discriminaciones positivas, esta ley de circunstancias se ha mantenido, y el número de sus beneficiarios no ha parado de extenderse. Desde 1929, los accidentes laborales entran en este perímetro, a pesar de que la Cámara de Comercio de París considera que los "privilegios concedidos a los mutilados de guerra encuentran su legitimidad en la naturaleza muy particular de la deuda que la nación tiene hacia ellos». Le seguirán las víctimas civiles de la guerra en 1948, las viudas y los huérfanos de guerra en 1955, los discapacitados físicos o mentales en 1957, las personas que padecen una enfermedad profesional en 1975 o las víctimas civiles de atentados en 1987. Institucionalizándose, esta política de cuota se ha desvinculado progresivamente de un sentimiento de solidaridad y de deuda colectiva. La definición de dichos beneficiarios se ha alejado de la percepción común de la discapacidad: el reconocimiento administrativo de ésta, que concierne a 1,3 millones de trabajadores, es concedido durante un periodo de dos, cinco o diez años. No es concedido a las personas con importantes discapacidades y no se refiere necesariamente a unas características visibles. Además, se ignora el número de discapacitados que, a pesar de estar integrados profesionalmente, no han solicitado el reconocimiento administrativo de su situación.

La Ley del 30 de junio de 1975 a favor de los discapacitados consta de un artículo relativo a su inserción, pero el uso de la palabra no hace referencia todavía a un modelo preciso de política pública. Ésta se concreta al final de la década de 1970. Las políticas de inserción elaborados entonces pueden analizarse como políticas de discriminación positiva, en el sentido 
de que «pueden entenderse como un conjunto de iniciativas de nivelación que se dirigen a colectivos particulares y a zonas singulares del espacio social, y despliegan a su intención estrategias específicas»" ${ }^{5}$. En materia de empleo, quieren facilitar el acceso al empleo de las personas excluidas del mercado laboral (jóvenes, personas poco cualificadas, desempleados de larga duración, personas mayores, beneficiarios de la renta básica). El número de sus beneficiarios, que ha culminado en 2,5 millones en 1999, se eleva hoy en día a 1,8 millones de personas. Inaugurados por los "pactos para el empleo de los jóvenes», que se han sucedido entre 1977 y 1982, las medidas destinadas a favorecer la inserción profesional de algunas categorías de la población pretendían ser experimentales, coyunturales y transitorias. A la imagen de las políticas de integración voluntaristas provenientes de la Ley de 1924, relativa a los mutilados de guerra, se han institucionalizado progresivamente.

Más recientemente, la cuestión del empleo ha sido abordada bajo el enfoque de la diversidad. El objetivo de la diversidad ha sido inicialmente formulado en el sector público. A partir de 1995, el ejército y posteriormente la policía, han manifestado su voluntad de "parecerse a la población». El tema se ha extendido al conjunto de la función pública. El informe Versini, de diciembre de 2004, atestigua del éxito fulgurante de este nuevo valor. En el sector privado, el impulso europeo ha sido decisivo. Llevado a cabo a nivel europeo, la campaña «Para la diversidad. Contra las discriminaciones (2003-2007)» ha intentado promover la idea de que la diversidad es una fuente de riqueza y de competitividad. La diversidad así promovida resulta de la combinación de cinco criterios: el origen étnico, la religión, la edad, la discapacidad y la orientación sexual. Estas diferencias deben ser valoradas por la sociedad en su conjunto y, más especialmente, por las empresas.

El mensaje europeo, en Francia, ha sido relevado eficazmente por el Instituto Montaigne, un think tank próximo al mundo empresarial. Ha invitado a los empresarios a "reflejar en sus filas los diversos componentes de la sociedad francesa» y a firmar, para materializar este compromiso, la "Carta de la diversidad» lanzada el 22 de octubre de 2004. El 12 de octubre de 2006, un acuerdo nacional interprofesional "relativo a la diversidad en la empresa» ha recibido la aprobación de la casi totalidad de los agentes sociales. El ANPE, equivalente del INEM español, y las agencias de interinos han decidido igualmente centrar su estrategia de comunicación sobre la diversidad. Lo ideal sería disponer de un mundo laboral a la imagen de la población. Para ello, «debería conducir a la instauración de cuotas, así como de numerus clausus». La realidad es bien distinta, puesto que la exaltación de la diversidad es puramente formal. Invita a una toma de conciencia sobre el riesgo discriminatorio en la empresa, abre la vía a los enfoques de formación y de sensibilización o a las movilizaciones positivas contra las discriminaciones.

5. R. CASTEL (1999). Les métamorphoses de la question sociale. París: Gallimard, p. 676. 


\section{La diversidad de las técnicas de intervención correctoras de las administraciones públicas}

Utilizada en numerosas políticas públicas, la técnica de la cuota, en materia de empleo, beneficia sobre todo a los trabajadores discapacitados. El dispositivo instaurado en 1924 se ha mantenido a lo largo de las décadas, aunque no haya dado buenos resultados. Incluso ha sido reforzado por la ley del $11 \mathrm{de}$ febrero de 2005 sobre la igualdad de derechos y de oportunidades, la participación y la ciudadanía de las personas discapacitadas. Se basa sobre la idea que una obligación de empleo pesa sobre los empleadores. Todos los empleadores que dirigen una empresa de más de veinte asalariados se ven sometidos a esta obligación de empleo $(6 \%)$, teniendo en cuenta que el número de trabajadores es de diez hasta 1987. Ni los empleadores públicos (53.000) ni los empleadores privados (más de 100.000) alcanzan este porcentaje en 2006, puesto que tienen tasas de empleo respectivamente del 3,6\% y del 2,7\%.

Este resultado es debido al hecho de que, si la obligación de empleo se analiza como una obligación de resultado, no se impone por lo tanto de manera ciega. Las empresas pueden exonerarse de dos maneras. Pueden negociar, en el límite del $50 \%$ de su obligación, los contratos de suministro, de subcontratación o de prestación de servicios con las entidades del sector protegido. Pueden igualmente, según un sistema clásico de pay or play, pagar una contribución de sustitución vertida anualmente a un fondo de desarrollo especializado: la Asociación para la Gestión del Fondo de Inserción Profesional. Esta segunda opción, que conduce finalmente a sancionar a los empleadores que no alcanzan los objetivos fijados, ha sido reforzada por la ley del 11 de febrero de 2005. La cuantía de la contribución ha sido aumentada considerablemente y, sobre todo, el sector público, que se escapaba hasta entonces de la lógica de la penalidad financiera, se ve sometido a ella.

Menos apremiante que la cuota, la fijación de objetivos cifrados (no vinculados a sanciones) concierne sobre todo al empleo femenino. Desde 1975, los empleadores no pueden tomar decisiones de contratación o de despido basándose en el sexo o la situación familiar. Para hacer efectivo el principio de no discriminación de género y reducir las desigualdades de situación heredadas del pasado, la Ley Roudy de 1983 ha ofrecido a las empresas la posibilidad de crear, a favor de las mujeres, medidas de discriminación positiva presentadas por el código del trabajo como «medidas temporales tomadas para el único beneficio de las mujeres y que pretenden establecer la igualdad de oportunidades entre hombres y mujeres, en particular remediando a las desigualdades de hecho que afectan a las oportunidades de las mujeres». La contratación prioritaria de las mujeres en puestos tradicionalmente masculinos y el establecimiento de cuotas en materia de promoción y de formación son fomentados por el Estado, que invita a los agentes sociales a poner en marcha planes para la igualdad profesional a través de los cuales la empresa puede decidir, con el apoyo financiero de los poderes públicos, fijarse unos objetivos cifrados a alcanzar en un plazo determinado.

Este dispositivo ha resultado ser completamente ineficaz. La movilización sindical ha sido muy débil y los trabajadores, en un contexto de viva tensión en 
el mercado laboral, se muestran reticentes a la idea de practicar políticas empresariales específicas. En cerca de veinte años, solamente treinta y cuatro empresas han negociado planes para la igualdad profesional y únicamente catorce de ellas se han beneficiado de una ayuda financiera del Estado. Parece, además, que el dispositivo ha sido más o menos desviado de su finalidad, puesto que las empresas concernidas son entidades ampliamente feminizadas que han utilizado el procedimiento con fines de recalificación de su mano de obra.

La técnica de subvencionar el empleo caracteriza a un gran número de políticas de inserción en el mercado laboral, especialmente dirigidas a los jóvenes. Desde la creación del contrato de empleo y formación, en 1975, las administraciones públicas tienen, bajo diversas formas, un enfoque similar. Consiste en asumir, directamente o indirectamente, una parte del coste salarial inducido por la contratación de un beneficiario de la política de inserción a través de la reducción de las cargas sociales, de la concesión de subvenciones, de desgravaciones fiscales o del reparto de primas. Desde 1981, el informe Schwartz recomienda aplicar este tipo de discriminación positiva a tres categorías de jóvenes: los jóvenes sin calificación, las chicas jóvenes y los hijos de inmigrantes. Otros subgrupos han sido identificados posteriormente. Pero, hoy en día, los jóvenes en general constituyen la mitad de los beneficiarios de la política de inserción profesional. Desde 1975, les han propuesto contratos de inserción, contratos de calificación, contratos de empleo y solidaridad, contratos urbanos, contratos de iniciativa y empleo, contratos de empleo joven o contratos de joven en empresa. La inestabilidad y la multiplicidad de los dispositivos no contribuyen a su eficacia.

A menudo, la evaluación de estas políticas deja mucho que desear. Su impacto real sobre la reducción del número de desempleados y sobre las creaciones de empleo sigue siendo mal conocido. Están marcadas, como cualquier política preferente, por efectos de sustitución, cuya amplitud es difícilmente medible: la prioridad concedida a esta categoría de desempleados va en detrimento de otras categorías. Se observa un movimiento de recomposición de la fila de espera del desempleo. Por otra parte, el carácter transitorio del dispositivo, desde el punto de vista de sus beneficiarios, parece estar mal asegurado: la Cour des comptes, en su informe remitido al Senado en febrero de $2007^{6}$, subraya que «la hipótesis de una transición progresiva de los contratos ayudados hacia el empleo no ayudado, prácticamente no se confirma en la realidad». Se constatan fenómenos de fijación de los beneficios en los escalafones que sólo ofrecen un acceso limitado al empleo no ayudado.

En materia de acceso al empleo público, el debate sobre la discriminación positiva es lanzado en 1982 por la creación de una tercera vía de acceso a la Escuela Nacional de Administración (ENA). Al lado de la oposición externa abierta a los jóvenes diplomados, y de la oposición interna, destinada a los que ya pertenecen a la Administración, se reserva una tercera vía a los candidatos

6. «Communication relative à l'impact des contrats aidés». Sénat, rapport d’information, nº s255 (2006-2007). 
dotados de una experiencia de cargo electo local, de militante sindical o de responsable asociativo. El objetivo enunciado por la ley que instituye esta nueva vía de acceso es la democratización del sector público. Se trata, en la continuidad del espíritu que ha presidido durante varios años a la generalización de las oposiciones internas en la función pública, de trabajar a favor de la movilidad social, dando una verdadera oportunidad de integrar la ENA a los candidatos alejados de los universos escolar y administrativo.

Sin embargo, esta diferenciación de las vías de acceso al empleo público se desarrolla en nombre de la diversidad. El Consejo Constitucional lo analiza bajo este punto de vista en su decisión del 4 de enero de 1983, titulada Tercera vía de acceso a la ENA. Indica que el principio de igual admisibilidad al empleo público «no se opone a que las reglas de contratación sean diferenciadas para tener en cuenta tanto la variedad de los méritos a tomar en consideración como las necesidades del servicio público». El Consejo subraya igualmente que, lejos de tener un carácter absoluto, la noción de mérito se entiende siempre relativamente a un contexto o a una misión determinada. Tratándose del servicio al Estado, el Consejo se ha inclinado ante la valoración realizada por el legislador, que ha apostado por que las personas titulares de un mandato electivo, sindical o asociativo "presentan cualidades de competencia, de experiencia y de desinterés que hacen presumir de su aptitud a presentarse a una oposición de contratación que tiene como objeto averiguar su capacidad y elegir a los mejores».

La oposición especial organizada en 1983 surte efecto a lo largo de la escolaridad en la ENA. Efectivamente, los alumnos seleccionados a través de esta vía no tienen vocación de concurrir en pie de igualdad con sus camaradas para la clasificación de salida: su trayectoria está sancionada por una clasificación de salida distinta, puesto que la reforma les ha reservado, en el marco de una discriminación al estilo indio, una plaza sobre cinco en cada uno de los cuerpos a los que conduce la escuela. Este sistema fue abolido en 1986, pero reestablecido en 1990 bajo una forma modificada que suprime especialmente la «reserva» de los puestos de salida. Otras escuelas de la función pública se han dotado de una tercera oposición (Escuela nacional de la magistratura, institutos regionales de administración) e incluso de ciertos cuerpos de funcionarios. Por ejemplo, en 2003, el de los administradores de la función pública territorial. Las plazas propuestas no son numerosas, pero la Administración quiere mostrar así que se abre a la sociedad civil.

En el periodo reciente, otras vías derogatorias están igualmente exploradas al beneficio de los jóvenes cualificados. Por ejemplo, los Pacte (trayectorias de acceso a las carreras de la función pública territorial, hospitalaria y de Estado), creados en 2005, son contratos que evitan la barrera de las oposiciones, con lo cual permiten la contratación de jóvenes que, seguramente, no habrían sido seleccionados de otra forma.

\section{Las politicas en vía de modernización}

Las políticas de lucha contra las desigualdades en el acceso al empleo han entrado, hoy en día, en una fase de profunda renovación. La cuota y la subvención, 
instrumentos clásicos del intervencionismo estatal, están cada vez más desfasados con la construcción del mercado único, y un cambio de perspectiva tiende a desplazar una acción pública centrada en los destinatarios de las políticas de inserción hacia el lugar de su inserción, es decir, el mercado que se intenta controlar para que sea menos impulsivo. Los nuevos instrumentos de estas políticas rechazan cualquier tratamiento preferente e incluso cualquier medida abiertamente específica. Intentan orientar el comportamiento de los actores económicos adoptando una actitud de regulación flexible. El objetivo es orientar a los mercados siguiendo su propia lógica en lugar de someterlos a una presión externa.

Los instrumentos disponibles con este fin están en vía de integración en el repertorio de las políticas públicas francesas: el outreach, el monitoring y el mainstreaming.

1. El outreach reúne a varias iniciativas de identificación de las candidaturas potenciales y de fomento de su concreción. Se trata de la prolongación de estas campañas de información que intentan, desde hace mucho tiempo, convencer a las mujeres jóvenes que ninguna profesión no es "por naturaleza» masculina, de buscar activamente las categorías de desempleados que unos obstáculos objetivos y subjetivos mantienen al margen de ciertos empleos o de algunas empresas.

Para los empleadores públicos que conocen o que anticipan dificultades de contratación, se trata de presentarse ante los jóvenes que desconocen su existencia, conocen mal las vías de acceso a la función pública o consideran que no tienen ninguna oportunidad de acceder a ella. La puesta en marcha del outreach supone, por su parte, una colaboración reforzada con el Ministerio de Educación, así como la utilización de técnicas de comunicación menos convencionales, tales como los estands de iniciación en el parking de los centros comerciales o las operaciones de comunicación que se dirigen específicamente hacia algunas categorías de la población. La SNCF ha lanzado, estos últimos años, operaciones de contratación que se dirigen muy explícitamente a los habitantes de los suburbios urbanos. El Ministerio del Interior organiza igualmente, desde 2005, con la empresa de contratación y de trabajo temporal Vediorbis, las jornadas «Seguridad y Ciudadanía», destinadas a «valorizar la imagen de la policía nacional» ante un público de jóvenes provenientes de los barrios populares.

Un número creciente de grandes empresas privadas adoptan la misma actitud, tanto para compensar los efectos de un juicio por discriminación (L'Oréal, Ikea, Addeco), como para cambiar la imagen que la opinión pública tiene de ellas. Así, en junio de 2003, EADS lanzó una campaña publicitaria que anunciaba que sería fomentada, en el seno de la empresa, una actitud proactiva en materia de contratación femenina, especialmente en las funciones de ingeniería. Para diversificar sus vías de contratación, estas empresas pueden colaborar con asociaciones o centros educativos situados en los territorios prioritarios de la política urbana. Pueden, igualmente, dirigirse hacia viveros 
especializados cuya formación está fomentada por los poderes públicos. El Fondo de Inserción Profesional de las Personas Discapacitadas les propone, así, «ir al encuentro de los futuros colaboradores discapacitados», participando en foros o eligiendo en una base de datos que reúne los curriculum vitae de los directivos discapacitados. En el mismo espíritu, los contratistas están incitados a realizar un anuncio a favor de la diversidad sobre la página de Internet diversidad-empleo.com.

La adopción de una actitud outreach supone una política de anuncio cuidadosamente concertada. Para convencerse de que la discriminación no es una fatalidad, conviene decirlo alto y fuerte, elaborando un programa de acción, firmando una carta (carta deontológica, carta de la diversidad, carta para la igualdad de oportunidades) o concluyendo un convenio con la Halde, un ministerio o una asociación de barrio. Las empresas pueden marcar los espíritus con acciones espectaculares: anunciar que esconderán, como para una oposición de la función pública, el nombre, la edad y la dirección del solicitante (curriculum vitae anónimos); renunciar completamente a solicitar el CV (método de contratación por simulación), o evitar puntualmente los procedimientos habituales de la contratación, organizando encuentros a ciegas entre contratistas y desempleados (técnica de job dating).

La concesión de un label oficial puede coronar esta microgestión de la nodiscriminación. A la imagen de las banderas arco iris que adornan la fachada de los centros gay friendly, sus logotipos aparecen por todas partes: Label Igualdad, Triunfo Fraternidad, Label Social para la Igualdad de Oportunidades, Label Turismo y Discapacidad o Label Senior. Se intentan también promover modelos de identificación positiva, valorizando, por ejemplo, el éxito profesional de los jóvenes talentosos: cada año, los galardonados de la operación Talentos de los Suburbios, lanzado en 2002 en el marco de la política urbana, tienen vocación de jugar en su barrio y más allá el papel de «embajadores del éxito».

2. El monitoring designa una actividad de vigilancia activa de los procesos discriminatorios y de sus efectos. El objetivo es poner el énfasis sobre las situaciones de desigualdad estructural, hacer aparecer las discriminaciones intencionales o sistémicas, poner de manifiesto el desequilibrio inducido por tal o tal práctica empresarial. El monitoring, así como el outreach, no incide directamente en el comportamiento de los agentes económicos. Se fundamenta en un modelo de regulación favoreciendo la transparencia del mercado (sunshine regulation) que deja a los actores sociales la responsabilidad de proceder a los ajustes necesarios.

Esta perspectiva está ilustrada por la Ley Génisson, del 9 de mayo de 2001, relativa a la igualdad profesional entre hombres y mujeres, que completa la Ley Roudy. Esta Ley de 1983 ya imponía a los empleadores redactar un «informe anual sobre la situación comparada de las condiciones de empleo de las mujeres y de los hombres». Pero esta obligación estaba respetada por menos de la mitad de los empleadores y, sobre todo, la información comunicada era 
demasiado global para ser significativa. La presentación por la empresa del salario medio de los hombres y mujeres, por ejemplo, constituye un dato desprovisto de cualquier significado si es imposible relacionarlo con otros elementos tales como la antigüedad media en el puesto de trabajo, el nivel de instrucción, etc. La formulación de indicadores precisos y aplicables uniformemente en todas las empresas de más de cincuenta trabajadores ha cubierto esta laguna del dispositivo. Desde entonces, los empleadores se ven obligados cada año, sobre la base de indicadores fijados por decreto, a redactar un informe sobre la situación comparada de los hombres y de las mujeres en la empresa. Este informe sirve de fundamento a la negociación colectiva anual sobre los objetivos en materia de igualdad profesional y los medios de alcanzarla.

Sobre este modelo de monitoring de la igualdad entre hombres y mujeres, la creación de un monitoring etnorracial ha sido propuesta con una insistencia creciente. ¿Cómo evaluar la amplitud de las discriminaciones y controlar los progresos realizados por las empresas, si no se dispone de un instrumento de medida ad hoc? Denunciando la «opacidad estadística» impuesta por la legislación francesa, algunos empresarios desearían dotarse de «los medios necesarios para medir las discriminaciones» ${ }^{7}$. Reclaman la posibilidad de hacer aparecer en sus ficheros de gestión, además del sexo y de la edad de los asalariados, su origen etnorracial. Gracias al apoyo de grupos de presión como el CRAN (Consejo Representativo de las Asociaciones Negras), esta demanda de etnicización de los ficheros ha seducido a ciertos actores de este debate.

No obstante, desde un punto de vista estrictamente técnico, los datos recogidos a nivel de una empresa no tienen ningún sentido si no se comparan con datos más generales. ¿Qué se puede concluir de la ausencia de asiáticos en una fábrica del Doubs, si se desconoce el número de asiáticos residentes en esta región y la cantidad de personas dotadas de las cualificaciones exigidas para pretender ocupar un puesto en esta fábrica? Todos los países que practican el monitoring etnorracial en el ámbito del empleo disponen de una nomenclatura nacional de las categorías etnorraciales, y los datos socioeconómicos que recogen son casi sistemáticamente etnicizados. Por ello, ¿conviene involucrarse en la elaboración de este referencial nacional etnorracial? Las consultas organizadas por la CNIL en 2006 y 2007 han demostrado que esta propuesta generaba una aprobación limitada. El Consejo Constitucional ha puesto un término a la discusión, censurando una disposición legislativa que pretende flexibilizar las condiciones en las cuales pueden ser conducidos unos estudios que miden «la diversidad de los orígenes, de las discriminaciones y de la integración» ${ }^{8}$. El impacto de esta decisión es incierto en razón del carácter lapidario de su motivación y de las condiciones en las cuales se ha deferido la ley.

7. C. BÉBÉAR (2004). Des entreprises aux couleurs de la France. Informe dirigido al primer ministro. París: La Documentation Française, p. 14.

8. Decisión del 15 de noviembre de 2007, Ley relativa al control de la inmigración. 
3. El mainstreaming, o acción integrada, intenta prevenir la discriminación indirecta, es decir, eliminar las disposiciones o prácticas que, aparentemente irreprochables, corren el riesgo, una vez implementadas, de crear o de agravar una desigualdad de situación. Consiste en evaluar sistemáticamente los efectos potencialmente discriminatorios de una medida. Es cuestión de plantear la problemática del género, de la discapacidad o de la etnia a todas las políticas públicas, en materia tanto de empleo como de protección social o de transportes. Una medida tomada en beneficio de los trabajadores a tiempo parcial, por ejemplo, no será únicamente analizada en sus implicaciones económicas y sociales. Se tendrá igualmente en cuenta el hecho de que favorece objetivamente a las mujeres, que, más que los hombres, trabajan a tiempo parcial. Aplicada al género por las autoridades de Bruselas desde 1995, este enfoque ha sido extendido a la discapacidad en 1997, y, en 1998, a las víctimas potenciales de las discriminaciones racistas u homófobas.

Así, las empresas están incitadas a realizar un estudio de impacto para cada una de sus prácticas, desde la organización de la jornada laboral hasta el menú de las comidas, pasando por las ventajas concedidas a las familias de los asalariados. ¿Estas prácticas corren el riesgo de ocasionar un prejuicio a aquéllos que están dotados de una característica que les distingue de la mayoría? El principio del "concebido para todos» conduce a anticipar estas consecuencias diferenciadas y a intentar reducirlas lo máximo posible. Medidas de ordenación del territorio razonables garantizan, por ejemplo, la accesibilidad de los edificios a los discapacitados. Empresas públicas como EDF o La Poste asumen el hecho de que la prioridad concedida a los hijos de los trabajadores de la empresa para acceder a las prácticas de estudiantes ha sido excluyente durante un largo periodo.

Los agentes económicos están, por lo tanto, incitados a explicitar los criterios que orientan sus prácticas, a evaluar sus efectos concretos y a cuestionar sus fundamentos. En este caso, también, el objetivo es convertir el mercado en más inclusivo, respetando su propia lógica.

\section{La igualdad de género en la esfera pública}

La paridad es presentada como una contribución específicamente francesa a la teoría y a la práctica de la discriminación positiva. Por la amplitud del debate público que despierta, por la profundidad de sus fundamentos filosóficos, por la radicalidad de las medidas concretas finalmente aprobadas, la paridad puede ser erigida en modelo de una política de recuperación entre dos grupos desiguales: los hombres y las mujeres en política. Semejante presentación no carece de pertinencia, pero oculta la originalidad principal de una política cuya constitucionalidad ha sido valorada a tenor de la doctrina de la soberanía nacional. Esta manera, sin duda única en el mundo, de enfocar el problema de la igualdad entre hombres y mujeres es el fruto, paradójicamente, de una cierta normalización de la democracia francesa: el juez constitucional se convierte en un actor político y participa activamente en la definición de diferentes medi- 
das preferentes destinadas a hacer advenir la igualdad de género en la esfera pública.

\section{El igual acceso a los mandatos electivos y a las funciones electivas}

1. Desde las cuotas de las mujeres en las elecciones municipales propuestas en 1975 hasta la revisión constitucional de 1999, la campaña para la paridad en política ofrece el ejemplo inédito en Francia de una reivindicación colectiva cuyos términos han sido elaborados para formar el espejo invertido de una decisión tomada por un juez que ocupa pocas veces las portadas de los periódicos: el juez constitucional.

La idea de las cuotas de mujeres en las listas electorales fue lanzada en 1975 por Françoise Giroud, secretaria de Estado de la Condición Femenina. Más exactamente, proponía limitar la proporción de los candidatos del mismo sexo en las elecciones municipales. Esta idea fue acogida por la clase política con un entusiasmo proporcional a sus motivaciones electoralistas. En diciembre de 1980, el primer ministro Raymond Barre hacía aprobar por la Asamblea Nacional, casi por unanimidad, un proyecto de ley que fijaba al $80 \%$ el límite de los candidatos de un mismo sexo que Françoise Giroux proponía de establecer en el $85 \%$. Pero el texto no ha sido debatido nunca en el Senado. En noviembre de 1982, el Parlamento proveniente de la alternancia de 1981, aumentando de cinco puntos las propuestas de Giscard d'Estaing, aprobaba una disposición que preveía que las listas de candidatos no podían tener más del 75\% de personas del mismo sexo. Pero la oposición, cuestionando la constitucionalidad de una disposición de la ley relativa a las elecciones municipales, difirió el texto al Consejo Constitucional, que lo declaró contrario a la Constitución.

Los términos en los cuales fue formulada la decisión del Consejo han influido de manera determinante en la evolución posterior del debate. El juez constitucional, que habría podido referirse al principio en virtud del cual «la ley garantiza a la mujer, en todos los ámbitos, derechos comparables a los de los hombres», ha preferido posicionarse sobre un terreno muy alejado al de la cuestión de la igualdad de género o, más generalmente, de la técnica de la discriminación positiva. Analizando las cuotas desde otra perspectiva, ha considerado que la indivisibilidad de la soberanía, la indiferenciación de la ciudadanía, la igualdad ante la ley y el acceso a las «"dignidades, plazas y empleos públi$\cos ^{\prime \prime}$ se oponen a cualquier división por categorías de electores o de elegibles». El sexo es un criterio de diferenciación inaceptable, porque la ciudadanía es asimilada al ciudadano. Por lo tanto, el juez no censura una discriminación, sino la distinción como tal. Así, se extiende a las mujeres, en materia de representación política, el compromiso tomado por el primer artículo de la Constitución, al término del cual la República «asegura la igualdad ante la ley 
de todos los ciudadanos sin distinción de origen, de etnia o de religión». El razonamiento desarrollado por la decisión del 18 de noviembre de 1982 conduce el debate sobre la igualdad entre hombres y mujeres en la esfera pública hacia una controversia sobre los principios republicanos.

Marcada por el lanzamiento, en el seno del Consejo europeo, de diferentes trabajos sobre la democracia paritaria, el año 1989 constituye el punto de partida que acaba poniendo boca abajo, en julio de 1999, el obstáculo constitucional. La progresión constante de la idea paritaria está jalonada, a lo largo de la década, por una serie de tiempos fuertes. En noviembre de 1992, como conclusión de un programa de acción de la Comunidad Europea, la Declaración de Atenas ofrece a la reivindicación paritaria un marco transnacional que las francesas sabrán aprovechar con prontitud y eficacia. «La necesidad de llegar a un reparto equilibrado de los poderes públicos y políticos entre hombres y mujeres» está reivindicada como derecho, y justificada, en nombre del interés general, en una perspectiva más pragmática. Este doble componente de la reivindicación paritaria se encuentra en el discurso de la red Mujeres por la Paridad y de personalidades que han relevado, en Francia, las iniciativas europeas. La red Mujeres por la Paridad publica, en noviembre de 1993, el Manifiesto de los 577 para una democracia paritaria, por el cual 289 mujeres y 288 hombres reclaman la aprobación de una ley que prevé que «las asambleas elegidas tanto a nivel territorial como a nivel nacional, están compuestas de tantos hombres como mujeres. Ha llegado la hora de mirar las cosas de frente. El medio siglo que acaba de terminar muestra que el acceso a las responsabilidades está bloqueado. Las cosas solo cambiarán a través de la ley».

Sin embargo, en el contexto francés y teniendo en cuenta la decisión del Consejo Constitucional, es esencial, desde un punto de vista estratégico, distinguir cuidadosamente la paridad de la cuota y demostrar su compatibilidad con los principios republicanos.

- Por una parte, los promotores de la paridad han subrayado que se distingue de la cuota por su filosofía misma. El enfoque de la cuota funciona por niveles sucesivos allá donde la paridad quiere fundar en seguida una sociedad cogestionada por los hombres y las mujeres. El reconocimiento del derecho a la paridad de los sexos consagra a nivel institucional, «el carácter bisexuado de la población, del electorado, de la humanidad" y manifiesta que «la democracia funciona por fin sobre sus dos piernas, mientras que la cuota sólo es un cataplasma sobre una pierna de madera».

- Por otra parte, convenía demostrar que el universalismo postulado y ratificado por la decisión de 1982 es un universalismo engañoso, heredado de una época en la cual las mujeres estaban completamente excluidas de la vida política. «El hombre universal, así como el ciudadano, era el ser humano masculino exclusivamente. El universalismo de 1789 era lo más particularista y comunitarista posible. La Revolución ha instaurado la comunidad política de los barones, libres e iguales en derechos». Contra este universalismo abstracto, conviene avanzar que «la ciudadanía no es reducible 
al ciudadano" y reclamar el reconocimiento de la dualidad del género humano. El hecho de subrayar que las mujeres forman la mitad de la humanidad y no una categoría, un grupo o una comunidad, permite hacer frente a autores, a la imagen de Elisabeth Badinter, que acusan a la paridad de conducir Francia hacia «la democracia comunitaria importada de los Estados Unidos» y hacia las reivindicaciones particularistas que le son inherentes.

Estas tesis han sido defendidas públicamente por el Manifiesto de las diez para la paridad, publicado el 6 de junio de 1996 en el Express. Diez antiguos ministros, tanto de derecha como de izquierda, describen «la indiferencia condescendiente, el desprecio, incluso la hostilidad declarada a las que se enfrentan las mujeres en política». Sin llegar a incriminar explícitamente la doctrina de la soberanía nacional sobre el cual se había fundado, en 1982, la decisión de invalidación de las cuotas, critican el jacobinismo, núcleo duro de la cultura republicana que se concentra en los valores viriles. Consideran que ha llegado la hora de «feminizar la República: la mirada de las mujeres, su experiencia, su cultura hacen falta en la elaboración de las leyes». Esta campaña a favor de la paridad desemboca, diecisiete años después de la invalidación de las cuotas por sexo en las elecciones municipales, en una revisión de la Constitución. La ley constitucional del 8 de julio de 1999 introduce, en el artículo 3 de la Constitución, un nuevo párrafo, al término del cual «la ley favorece el igual acceso de las mujeres y de los hombres a los mandatos electivos y a las funciones electivas». Los partidos y las formaciones políticas, precisa el artículo 4, "contribuyen a la puesta en marcha de este principio en las condiciones determinadas por la ley».

2. La ley del 6 de junio de 2000, que tiende a favorecer el igual acceso de las mujeres y de los hombres a los cargos electivos y a las funciones electivas, ha sido aprobada sobre la base de estas nuevas disposiciones constitucionales.

Por una parte, comparándolo con sus precursores escandinavos, indios, italianos, belgas y griegos, el dispositivo francés se caracteriza por su radicalidad. Excepto en las elecciones presidenciales, cantonales y parcialmente municipales para los municipios de menos de 3.500 habitantes, la ley del 6 de junio de 2000, modificada en 2003 y 2007, somete la casi totalidad de las elecciones políticas a la obligación de respetar las reglas paritarias. Consta de una dimensión impositiva y de una parte solamente incitativa.

- El mecanismo se impone a la totalidad de los escrutinios de lista. Dos regímenes diferentes son aplicables, según que la elección se desarrolle a una o dos vueltas. Cuando se trata de una elección a una sola vuelta (concierne igualmente a las elecciones regionales desde 2003), el principio es el de una estricta alternancia entre hombres y mujeres. Estas listas se denominan «igualdad alternada». Para las elecciones a dos vueltas, el principio retenido (destinado a facilitar las negociaciones que acompañan, entre las dos vueltas, el proceso de fusión de las listas), es el de un número similar de 
hombres y de mujeres por tramos de seis candidatos. La combinación elegida incumbe a la responsabilidad de los partidos. Para estos escrutinios de lista, la paridad es obligatoria, ya que la lista que no satisface a las condiciones fijadas por la ley es anulada.

- Para los escrutinios uninominales, especialmente en las elecciones legislativas, el legislador ha elegido el mecanismo de la penalidad financiera. El principio es que un partido debe proponer al sufragio universal tantas mujeres como hombres. El respeto de este principio permite a los partidos percibir la totalidad de la ayuda pública prevista por la ley. Si el partido no alcanza esta tasa ideal de candidatos de cada sexo, se ve sometido a una sanción de una cuantía comparable a la mitad de la diferencia observada entre la tasa legal y la tasa efectiva de candidatos. Un partido que sólo habría presentado un $20 \%$ de mujeres vería así su subvención amputada en un $15 \%$.

Por otra parte, la aplicación de esta ley del 6 de junio de 2000 ha producido, durante las diferentes elecciones que han tenido lugar en 2001, 2002, 2004, 2007 y 2008 , unos resultados variables.

- Según los optimistas, el balance, a pesar de ser insuficiente, es alentador. Insisten en los efectos directos, pero también indirectos, producidos por la ley. Algunos efectos directos son indiscutibles: la ley del 6 de junio de 2000 ha permitido la entrada masiva de las mujeres en las corporaciones de los municipios de más de 3.500 habitantes, donde su proporción alcanza cerca del $50 \%$ (frente al $25,7 \%$ anterior a la aplicación de la paridad). Este efecto directo se ha hecho sentir igualmente, de manera menos nítida, en la renovación trienal del Senado en 2001: 22 mujeres figuraban entre los 102 senadores elegidos o reelegidos, frente a las 7 anteriores. Este progreso es exclusivamente imputable a la aplicación de las reglas de paridad, puesto que los pequeños departamentos, que estaban sometidos a la legislación anterior, han designado 26 senadores y 2 senadoras, es decir, una proporción exactamente idéntica al ratio de la elección anterior. La reforma del 30 de julio de 2003 ha demostrado que, por el contrario, la obligación paritaria seguía siendo indispensable, puesto que, restableciendo la aplicación del escrutinio mayoritario, ha conllevado, durante la renovación trienal de septiembre de 2004, una vuelta al statu quo. Si el Senado cuenta hoy en día con un $17,5 \%$ de mujeres, esta proporción corre el riesgo de disminuir durante la renovación de septiembre de 2008.

Entre los efectos indirectos, se puede citar, en primer lugar, el efecto llevadero que ha marcado los escrutinios que escapan a la influencia de la ley de paridad. Así, en los municipios de menos de 3.500 habitantes, el porcentaje de mujeres elegidas en marzo de 2001 ha pasado del $21 \%$ al 30\%. Asimismo, al término de la elecciones cantonales de 2001 y 2004, la parte de las mujeres consejeras generales ha progresado en uno o dos puntos. Se trata de un estremecimiento modesto pero real. La ley del 31 de enero de 
2007 ha querido, además, acompañar este progreso imponiendo al titular de un mandato de consejero general la obligación de dotarse de un sustituto del sexo opuesto. En segundo lugar, los optimistas apuestan por la iniciación de un proceso. Así, la ley ha incitado a los partidos políticos a presentar un 38,9\% de mujeres durante las elecciones legislativas de junio de 2002, lo que representa un avance con respecto al $22 \%$ de la precedente consulta y que, sobre todo, puede analizarse como una vuelta de calentamiento. Es cierto que este pronóstico no ha sido confirmado por el pequeño salto dado en 2007 con el 41,6\% de mujeres entre los candidatos.

- Otros observadores hacen un balance claramente negativo de la aplicación de la ley de 6 de junio de 2000. Proponen, en primer lugar, una visión menos positiva del resultado de las elecciones municipales de 2001, haciendo valer que el éxito de la paridad a nivel municipal es ilusorio: si un tercio de los concejales municipales son mujeres, el acceso a las funciones ejecutivas se les escapa ampliamente, ya que el porcentaje de mujeres alcaldes sigue siendo inferior al $11 \%$, así como la presidencia de las estructuras intermunicipales (dirigen el 5,4\% de los centros públicos de cooperación municipal, 4 comunidades de aglomeración sobre un total de 120 y ninguna comunidad urbana). No obstante, la situación ha evolucionado después de las elecciones de marzo de 2008, en la medida en que la ley del 31 de enero de 2007 ha extendido la obligación de la paridad a los procedimientos de designación de los ejecutivos municipales para los municipios de 3.500 habitantes y más.

Pero son sobre todo los resultados de las elecciones legislativas de junio de 2002 y 2007 los que ofrecen a los críticos de la ley paritaria su argumento principal. Efectivamente, estas elecciones han permitido a la proporción de mujeres diputadas superar la barrera del $12 \%$ en 2002 para alcanzar el $18,5 \%$ en 2007, mientras que hasta entonces esta proporción era inferior al 11\%. Las principales formaciones políticas han aceptado esta medida legislativa forzosamente y en contra de su voluntad. Han presentado menos candidatas que las pequeñas formaciones políticas y, cuando lo han hecho, las han presentado en circunscripciones difíciles de ganar. En lugar de aceptar las reglas del juego, los hombres que controlan las comisiones de investidura han preferido pagar, es decir, renunciar a una parte de las ayudas públicas. No obstante, el endurecimiento de las sanciones financieras impuestas por la ley del 31 de diciembre de 2007 surtirá probablemente efecto en 2012.

Por último, la paridad en política ha generado un intenso debate filosófico y teórico y ha movilizado, durante varios años, a una parte del mundo académico y de la clase política francesa. Sin embargo, comparativamente, los resultados son limitados. Se admite que la ley del 6 de junio de 2000 puede ser revisada a la baja sin que el Consejo Constitucional emita un informe desfavorable: un ataque a la dinámica paritaria no se analiza como un ataque a un principio constitucional. En dos ocasiones, en 2003 (el 3 de abril y el 24 de julio), el Consejo ha considerado que las leyes que corrían el riesgo de redu- 
cir las oportunidades de las mujeres en el ámbito de las negociaciones partidistas eran conformes a la Constitución. Sin entrar en el detalle de las disposiciones criticadas, se puede subrayar que la ley relativa a la elección de los representantes al Parlamento europeo, sustituyendo una circunscripción nacional única por ocho circunscripciones interregionales, enfrentaba a los partidos a la tentación de reducir la proporción de mujeres en posiciones elegibles. El Partido Socialista, por ejemplo, no ha resistido a dicha presión: sobre las ocho listas que han defendido sus colores en las elecciones europeas de junio de 2004, siete estaban encabezadas por hombres. Asimismo, la ley de julio de 2003 relativa a la elección de los senadores, ha elevado de tres a cuatro el número de escaños a partir de los cuales la elección se desarrolla según la representación proporcional. Por consiguiente, tiene pocas probabilidades de acelerar el movimiento de feminización del Senado.

No obstante, el Consejo ha dado su visto bueno a este debilitamiento de la obligación paritaria avanzando dos argumentos jurídicos: «las disposiciones criticadas no tienen, ni como objeto ni por ellas mismas, como efecto reducir la proporción de mujeres elegidas» (el control de constitucionalidad practicado en Francia es un control abstracto que no toma en consideración las condiciones posteriores de aplicación de la ley). Las nuevas disposiciones constitucionales «no tienen como objeto y no deberían tener como efecto privar al legislador de la capacidad que le confiere el artículo 34 de la Constitución de fijar el régimen electoral de las asambleas». Llamado, en caso de conflicto, a apartarse ante otras reglas o principios constitucionales, la paridad se convierte en un mero objetivo legal de acceso de las mujeres y de los hombres a los mandatos electivos y a las funciones electivas.

3. Durante el punto culminante de la pelea de los años 1990 sobre la paridad en política, numerosos adversarios subrayaban el riesgo de abrir la caja de los truenos. Ceder sobre la paridad, precipitaría a Francia en la espiral del comunitarismo. No obstante, la predicción no se realizaría antes de varios años: «sustituya hombre-mujer por blanco-negro y, porque no, francés de origen y francés de origen magrebí: ¿quién lo aceptaría?», se pregunta Olivier Duhamel en un artículo publicado el 11 de julio de 1996. Diez años más tarde, la cuestión ha encontrado su respuesta. Hoy en día, está admitido que los representantes deben parecerse a los ciudadanos, es decir, que los partidos políticos, el gobierno y el Parlamento deben tener en su seno a una proporción razonable de representantes de la diversidad, dicho de otra forma, a personas que pertenecen, de cerca o de lejos, a grupos visibles. Para las elecciones legislativas de 2007 , así como para las elecciones municipales de 2008, los principales partidos se han comprometido, bajo la vigilancia de los medios de comunicación, en una verdadera carrera a la diversidad.

Como para las mujeres en la década de 1980, el ejecutivo ha abierto la vía procediendo al nombramiento de personalidades provenientes de la sociedad civil y novatos en política: Tokia Saïfi en 2002 (gobierno Raffarin), Azouz Begag en 2005 (gobierno de Villepin), Fadela Amara, Rama Yade y Rachida 
Dati en 2007 (gobierno Fillon). Excepto Rachida Dati, estas personalidades están poco marcadas políticamente y no han sido nombradas a cargos que las destinan a participar de manera activa en la dirección de la política gubernamental. Por lo tanto, su imagen pública se ha constituido a partir de su historia familiar, de su carácter, de su éxito. Nolens volens, han sido erigidas en símbolos del modelo francés de integración. Se trata de un símbolo tranquilizador, en la medida en que los jóvenes provenientes de la inmigración son percibidos, más que nunca, como las nuevas clases peligrosas de la sociedad.

El éxito de los nombramientos ante la opinión pública, gracias a una amplia mediatización, ha sido relevado por pequeños grupos de presión (Club XXI siglo, CRAN, etc.), que se han esforzado en difundir la tesis de una necesaria representación de las minorías visibles a través de la publicación de tribunas en la prensa, la búsqueda de padrinos y de figuras morales, la organización de coloquios y de debates públicos. A partir de entonces, la presión se ha desplazado hacia los partidos políticos, que se han sentido obligados a presentar candidatos que representen «los colores de una Francia plural y multicultural». No obstante, conviene no equivocarse sobre la idea de representación. No se exige a las personas provenientes de la diversidad que defiendan los intereses del grupo al que pertenecen. Si éste fuese el sentido atribuido a la noción de representación, la ausencia del parlamento de obreros o de empleados, que constituyen el $53 \%$ de la población, sería puesta de manifiesto. Tampoco se les pide que expresen la identidad de tal o tal comunidad. Se les exige simplemente que representen una metáfora.

\section{El igual acceso a las dignidades, a las plazas y a los empleos públicos}

En 1982, el artículo 3 de la Constitución relativo a la soberanía ha sido combinado con el artículo 6 de la Declaración de los derechos humanos y del ciudadano de 1789, para afirmar la inconstitucionalidad de las cuotas de género en las elecciones municipales. Puesto que el artículo 3 de la Constitución ha sido revisado en 1999 para superar la decisión del Consejo, ¿el artículo 6 de la Declaración puede prohibir al legislador emprender nuevas reformas de inspiración paritaria? El Consejo Constitucional responde afirmativamente. En los ámbitos no concernidos por la revisión, es decir, cuando el ejercicio de la soberanía nacional no es cuestionado, la paridad constituye un mero objetivo de rango legislativo, expuesto a las furias de la censura jurisdiccional.

1. Los intentos de extensión de la lógica paritaria más allá del ámbito electoral no han faltado. En 2001, y posteriormente en 2006, el Parlamento ha querido extender al ámbito profesional la lógica de las cuotas introducida en 2000 en la esfera electoral.

- La ley del 9 de mayo de 2001, relativa a la igualdad profesional entre hombres y mujeres, conocida como Ley Génisson, entendía hacer efectiva la Ley Roudy de 1983. En el seno de este marco, algunas disposiciones que 
conciernen más específicamente a la igualdad de género en la Administración pública. Considerando que la tasa de feminización de los miembros de los tribunales de las oposiciones no está desprovista de cierta incidencia sobre el porcentaje de mujeres admitidas o promocionadas, el legislador ha previsto que las comisiones administrativas paritarias, así como los tribunales y los comités de selección de los funcionarios, deberían estar compuestos de manera que puedan «concurrir a una representación equilibrada entre los hombres y las mujeres». Un decreto de aplicación del 3 de mayo de 2002 ha indicado que la expresión "representación equilibrada» debía comprenderse como sinónimo de "promoción mínima de un tercio de personas de cada sexo dotadas de las competencias necesarias».

- El objeto de la ley aprobada el 30 de mayo de 2001, inspirada en una iniciativa del legislador belga, era imponer una regla de paridad en los dos niveles de elección del Consejo superior de la magistratura. El objetivo era romper el «techo de cristal» al que se enfrentan las mujeres en uno de los pocos lugares de poder en donde la paridad ha sido alcanzada espontáneamente: la magistratura judicial. Sin embargo, en el CSM sólo constaba, en el momento en el cual el legislador se había apoderado del problema, una única mujer sobre los seis representantes de los magistrados. Las listas electorales, al término de la ley, debían estar elaboradas según un principio de estricta alternancia entre sexos, de manera que los colegios de grandes electores hayan sido formados por tantas mujeres como hombres. En un segundo nivel, este colegio habría designado, a partir de las listas paritarias, los seis miembros del CSM.

- Tal y como ha sido aprobada en diciembre de 2001, la Ley de modernización social instaura un dispositivo de aprobación de las competencias adquiridas a través de la experiencia. Esta medida debía permitir a los trabajadores que han forjado sus cualificaciones profesionales a través de su experiencia profesional, verla reconocida por un título universitario o profesional. Mientras que la experiencia de los hombres y de las mujeres en el trabajo se desarrolla en unas condiciones muy diferentes, el legislador había previsto que sería valorada por tribunales cuya composición debía concurrir, a la imagen de los jurados de la Ley Génisson, «a una representación equilibrada entre los hombres y las mujeres». Gracias a esta serie de medidas, el gobierno de Lionel Jospin y la mayoría parlamentaria que le apoyaba, ubican su acción en la prolongación de la revisión constitucional del 8 de julio de 1999; revisión que el ministro de Justicia de la época presenta en la Asamblea Nacional como punto de partida para la instauración de una verdadera democracia paritaria, en sus dimensiones política, social y profesional.

- El cambio de mayoría no ha obstaculizado esta voluntad de extender el recurso a las cuotas por sexo. El 23 de febrero de 2006, el Parlamento aprobó una ley relativa a la igualdad salarial entre los hombres y las mujeres, que imponía a las empresas públicas y privadas feminizar, hasta al menos el $20 \%$, a sus consejos de administración y comités de empresa. Se les con- 
cedía un plazo de cinco años. Los procedimientos de designación de los delegados del personal, de los consejos prud'hommales y de los organismos paritarios de la función pública debían conducir, en este plazo, al mismo resultado. Además, la ley invitaba a las regiones a incluir, en su plan de desarrollo, formaciones profesionales y de aprendizaje, con un objetivo de acceso equilibrado de los hombres y de las mujeres.

2. Todas estas medidas se han enfrentado al veto del Consejo Constitucional. Éste ha decidido solo, como lo hizo en 1982 a propósito de las cuotas por sexo en las elecciones municipales, hacer pesar su control sobre estas disposiciones cuya conformidad con la Constitución no estaba cuestionada por nadie.

En primer lugar, ha considerado como inconstitucional la cuota del 50\% instaurada por la elección del CSM (decisión del 19 de junio de 2001, Ley Orgánica relativa al estatus de magistrado), así como las diferentes cuotas instauradas por la ley de febrero de 2006 (decisión del 16 de marzo de 2006, Ley relativa a la igualdad salarial entre los hombres y las mujeres). Ha autorizado la promulgación de las demás medidas de feminización, a pesar de formular ciertas «reservas de interpretación» que lo reducen al rango de simples objetivos no obligatorios (decisión del 12 de enero de 2002, Ley de modernización social, y decisión del 16 de marzo de 2006). Por primera vez en su historia, ha aprovechado la oportunidad del análisis de la ley de modernización social para privar de cualquier carácter impositivo a las disposiciones paritarias de la Ley Génisson, que, habiendo escapado a su control, había entrado en vigor algunos meses antes. El Consejo de Estado ha dado su aval, en el Decreto Lesourd del 22 de junio de 2007, a esta iniciativa muy audaz.

En contra de la voluntad varias veces expresada por el legislador y el constituyente, el Consejo Constitucional ha limitado claramente el ámbito de aplicación de las técnicas paritarias. Las disposiciones constitucionales aprobadas en 1999 «sólo se aplican a las elecciones, a los mandatos y a los cargos políticos». En los demás ámbitos, sin embargo, se admite que la Constitución se opone a la edificación de «reglas obligatorias basadas en el sexo de las personas».

En segundo lugar, estas soluciones se han basado, en 2001 y 2002, en el artículo 6 de la Declaración de 1789, que proclama que todos los ciudadanos «son igualmente admisibles a cualquier dignidad, plaza o empleo público, según su capacidad, y sin otra distinción que la de sus virtudes y talentos». La calidad de miembro del CSM, así como la participación en diversos tribunales y comisiones administrativas, debe analizarse, según el Consejo, como la aceptación de una de estas dignidades, plazas y empleos públicos. No obstante, se puede preguntar si, tal y como lo había hecho en su tiempo Danièle Lochak a propósito de la decisión del 18 de noviembre de 1982, si la referencia al artículo 6 no está fuera de lugar. ¿Un magistrado está designado por sus homólogos para formar parte del CSM en consideración de estas virtudes y talentos? ¿No se le trata en mayor medida en función de su pertenencia sindical y, más ampliamente, de los intereses y de las posiciones que está decidido a defender? Si la ley instaura una representación proporcional, ¿no se trata 
precisamente de permitir una representación de las diferentes sensibilidades presentes en el cuerpo judicial? Tratándose de la designación de los miembros de los tribunales de la oposición, ¿̇no forman parte todos del mismo cuerpo de la función pública y, por lo tanto, son igual de competentes?

Enfrentado en 2006 a disposiciones que no conciernen solamente a la esfera pública, incluso entendida en un sentido amplio, el Consejo ha movilizado otros recursos constitucionales. Para censurar la cuota instaurada en materia de acceso a las responsabilidades profesionales y sociales, ha considerado que la discriminación a favor de las mujeres se enfrenta al artículo 1 de la Declaración, según el cual «los hombres nacen y siguen siendo libres e iguales en derechos. Las distinciones sociales no pueden basarse en la utilidad común", y en el artículo primero de la Constitución gala, que declara que «Francia garantiza la igualdad ante la ley de todos los ciudadanos, sin distinción de origen, de raza y de religión». Cualquier intento de extensión de la paridad fuera del dominio de las elecciones políticas debe, por lo tanto, contar con los obstáculos que el Consejo Constitucional está decidido a poner a su paso. El Consejo no se opone a las discriminaciones de derecho instituidas en vista a corregir las desigualdades de hecho. En materia de cálculo de las pensiones, por ejemplo, admite (decisión del 14 de agosto de 2003, Ley sobre la reforma de las pensiones) que "pertenece al legislador tomar en consideración las desigualdades de hecho de las que han sido objeto las mujeres hasta ahora» y que puede prever, para compensar sus efectos, «las disposiciones destinadas a compensar las desigualdades normalmente en vía de desaparición», es decir, muy precisamente, las medidas de discriminación positiva.

Es menos la discriminación positiva como tal que indispone al juez, como el uso de la técnica de la cuota. Las medidas de inspiración paritaria, como todas las discriminaciones positivas aprobadas en materia de acceso al empleo, ven desaparecer su carácter obligatorio. Su influencia efectiva depende, de ahora en adelante, de una forma de autodisciplina a la cual los actores económicos, sociales y políticos están condenados a someterse.

\section{Conclusión}

Recordemos que este artículo se ha interesado por las políticas de discriminación positiva que consisten en crear jurídicamente desigualdades para favorecer la igualdad de hecho. En el momento en el cual se impone el principio de no-discriminación, puede parecer paradójico recurrir a esta forma de acción positiva, cuya finalidad es llegar a una igualdad real, dando más a los que tienen menos. Todo ello genera una serie de cuestiones: ¿Cuáles son los fundamentos de la discriminación positiva? ¿En qué condiciones es aceptable? ¿Cuáles son sus formas y sus modalidades de aplicación? ¿Cuáles son sus resultados? El caso francés es interesante. A su propósito, hemos defendido la hipótesis según la cual, si la noción de discriminación positiva choca frontalmente con el principio republicano de igualdad de todos los ciudadanos ante la ley, en la práctica, además de tolerar su uso, las administraciones públicas fomentan las 
políticas de acción positiva en los ámbitos del empleo, de la paridad entre hombres y mujeres en la esfera pública y de la ordenación del territorio.

No obstante, la discriminación positiva contraviene a la igualdad de derechos y de oportunidades. Supone parcialmente la aplicación de principios que expresan valores morales y políticos considerados como fundamentales: igualdad ante la ley y los empleos públicos, igual acceso a la educación y al servicio público, libertad del elector o libertad contractual y derecho para el individuo de no estar asignado a un grupo de pertenencia. La discriminación positiva pone boca abajo el sentido de la preferencia concedida anteriormente a los blancos en detrimento de los negros o a los hombres en detrimento de las mujeres, pero mantiene la lógica de la preferencia. La valoración de los derechos y de los méritos consta sistemáticamente de dos niveles, por lo cual, es necesario, para prevenir el malestar e incluso la indignación que pueden suscitar las preferencias concedidas en función de semejantes criterios, establecer con certeza que la igualdad justifica el uso de la desigualdad.

\section{Bibliografía}

AtTal-Galy, Y. (2003). Droits de l'homme et catégories d'individus. París: LGDJ.

CONSEIL D'ÉTAT (1997). «Sur le principe d'égalité. Rapport public 1996». EDCE, no 48. París: La Documentation Française.

DOYTCHEVA, M. (2007). Une discrimination positive à la française?: Ethnicité et territoire dans les politiques de la ville. París: La Découverte.

LÉPINARD, E. (2007). L'égalité introuvable: La parité, les féministes et la République. París: Presses de Sciences Po.

SCHNAPPER, D. (2002). La démocratie providentielle: Essai sur l'égalité contemporaine. París: Gallimard.

WuHL, S. (2007). Discrimination positive et justice sociale. París: PUF. 